ISSN: 0212-0267

DOI: http://dx.doi.org/ro.I420I/hedu20I8374054I3

\title{
REOS, HUMILLADOS Y OFENDIDOS. \\ NUEVAS APORTACIONES SOBRE \\ LOS CATEDRÁTICOS DE BACHILLERATO \\ Y LA DEPURACIÓN FRANQUISTA
}

\section{Inmates, bumiliated and offended. New contributions on the professors of Bachillerato and the pro-Franco purification}

Raimundo Cuesta FernándeZ

Fedicaria-Salamanca

Correo-e: raicuesta2@gmail.com

Recepción: I6 de mayo de 20I8. Envío a informantes: 25 de mayo de 2018 Aceptación definitiva: $\mathrm{I}$ de julio de 2018

A propósito de libro de Moreno Burriel, Eliseo: Depurar y castigar. Los catedráticos de Geografía e Historia en los comienzos del Estado franquista, Zaragoza, Institución Fernando el Católico, 2018, 470 pp.

Resumen: Tomando como punto de partida una reciente tesis doctoral sobre la depuración de los catedráticos de Historia de la educación secundaria durante los primeros años de la dictadura franquista, en este artículo se hace un balance sobre las evaluaciones cuantitativas y cualitativas que tuvo la sistemática represión del profesorado y se presentan los avances historiográficos habidos en este tema así como el mejor conocimiento de la brutal lógica represiva del sistema político nacido de la Guerra Civil. Al mismo tiempo, se trata de defender una mirada que ponga más el acento en la comparación con otros cuerpos docentes y no docentes, de tal manera que en el futuro nos permita estimar sistemáticamente en su totalidad la dimensión numérica y cualitativa de la represión, pero también la racionalidad y múltiples paradojas de una política de castigo y terror ejercida sobre el profesorado y el conjunto de la sociedad española de la época. 
Palabras Clave: depuración; Educación Secundaria; catedráticos de Instituto; campo profesional; Archivo de la Administración Pública (AGA).

AвSTRACT: Taking as starting point a recent doctoral thesis on the purge of the professors of History of the secondary education during the first years of the Franco dictatorship, a balance is made on the quantitative and qualitative evaluations that had the systematic repression of the teaching staff and they are explained the historiographical advances made in this subject as well as the better knowledge of the brutal repressive logic of the political system born of the Civil War. At the same time, it is about defending a view that places more emphasis on comparison with other teaching and non-teaching bodies, in such a way that in the future it allows us to systematically estimate in its entirety the numerical and qualitative dimension of repression, but also the rationality and multiple paradoxes of a policy of punishment and terror exercised on teachers and the whole of Spanish society of the time.

KeY wORDs: Secondary Education; Secondary school teachers; profesional field; Archive of the Public Administration (AGA).

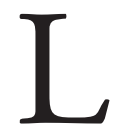

A TARDÍA ACCIÓN INVESTIGADORA acerca de la depuración de los cuerpos docentes ha constituido una de esas molestas y valetudinarias asignaturas pendientes de la historiografía hispana, constreñida entre las limitaciones impuestas por la Ley I3/1985 sobre Patrimonio Histórico y el débil entusiasmo del homo academicus a la hora de afrontar temas políticamente delicados, lo que a veces ha dejado esta clase de pesquisas en manos de voluntariosas y dispersas iniciativas individuales y locales. La reparación progresiva de este olvido mucho me malicio que obedece, además de a la progresiva extinción de los obstáculos jurídicos, al giro hacia la memoria histórica que se verifica en el panorama español en la coyuntura política acaecida entre los siglos XX y el XXI, una de cuyas consecuencias ha sido la quiebra del precario consenso político logrado en la Transición. Esta ruptura de los equilibrios y sobrentendidos abrió la incesante pugna entre una derecha que trata de relegitimar su naturaleza democrática mediante su apuesta por el revisionismo historiográfico y una izquierda que opta por destapar la caja de Pandora del recuerdo de quienes fueron vencidos. Aquí y ahora está por dilucidar quién finalmente se adueña y pinta los contornos esenciales de una narrativa hegemónica, capaz de traducirse en memoria colectiva, sobre el más traumático pasado reciente de España, porque, parafraseando a Orwell en su cacotópica novela 1984 , quien controla el presente controla el pasado y quien controla el pasado controlará el futuro.

Ciñéndonos al caso que nos ocupa, la depuración de lo que hoy se llama profesorado de secundaria, hasta 2005 no aparecen las primeras síntesis globales provenientes del mundo académico, fundamentalmente del campo de la historia de la educación. Las dos vías de acceso a este problema de investigación arrancan de la excelente documentación alojada en el Archivo General de la Administración 
Pública de Alcalá de Henares (AGA), en el que ha dormido el sueño del olvido la montaña de infamia convertida en legajos y reunida en torno a los expedientes de depuración del profesorado tramitados entre 1936 y 1943. Hoy los investigadores deben «agradecer» a la inquina represora franquista que ya desde 1936 se obligara a todo el profesorado a someterse a la purga para «demostrar» su inocencia, porque ello ha permitido conservar montañas de expedientes que son susceptibles de levantar el mapa sociopolítico de los cuerpos docentes en esos aciagos años. La primera síntesis sobre este proceso fue el hallazgo, gracias al buen hacer del profesor Olegario Negrín Fajardo, de un legajo en el AGA que contenía I.280 Expedientes resueltos del Cuerpo de catedráticos (no solo había catedráticos en tal relación), de cuya noticia e interpretación se hacía eco un inicial artículo escrito en Historia de la Educación, que actuó de primer bastidor de otros muchos que exprimían a fondo ese providencial legajo ${ }^{\mathrm{I}}$. La segunda visión global e innovadora procede del equipo de investigadores de la Universidad de Málaga formado por Isabel Grana Gil, Francisco Martín Zúñiga y Carmen Sanchidrián Blanco, que ya también en 2005 optarían por indagar el mismo problema en el AGA pero utilizando fuentes distintas y más completas que las empleadas por el profesor Negrín. En efecto, este grupo de historiadores acudía no a un listado conjunto sino a expedientes individualizados de profesores objeto de depuración, expedientes que alcanzan la cifra de 2.445 entradas $^{2}$. A partir de los resultados obtenidos por ambas vías de trabajo y apoyándome en el estudio evolutivo de los escalafones de catedráticos, yo mismo intenté una estimación global y comparativa del castigo sufrido por los docentes de los distintos cuerpos ${ }^{3}$. Allí, antes de que se hiciera público el libro objeto de este comentario, se mostraba que las cifras de sanción del cuerpo de catedráticos de Instituto eran demoledoras por sus

Negrín Fajardo, O.: «La depuración del profesorado de los institutos de segunda enseñanza. Relación de los expedientes resueltos por el Ministerio de Educación Nacional», Historia de la Educación, número 24 (2005), pp. 503-542. Cabe destacar, a efectos de la difusión de su trabajo fuera del gremio de los historiadores de la educación, la aportación de Negrín Fajardo, O.: «La depuración del profesorado de Segunda enseñanza en España durante la Guerra Civil y el franquismo», en Cuesta Bustillo, J. (dir.): La depuración de funcionarios bajo la dictadura franquista (1936-1975), Madrid, Fundación Largo Caballero, 2009, pp. 64-80.

2 Este equipo viene publicando progresivamente los resultados de su investigación a partir de los expedientes individualizados contenidos en el AGA. Ya en 2010 ofrecían una reconstrucción muy completa en Martín Zúñiga, F.; Grana Gil, I. y Sanchidrián Blanco, C.: «La depuración franquista de los docentes: control y sometimiento ideológico", Historia de la Educación, número 29 (20IO), pp. 24I-258; cuyos resultados, en buena parte, se reproducían en SANCHIDRIÁn BlanCO, C.; Grana Gil, I. y Martín Zúñiga, F.: «Análisis de los expedientes del profesorado de Institutos de Segunda Enseñanza en el franquismo (1946-1942). Resultados», Revista de Educación, número 356 (201I), pp. 377-399.

Cuesta Fernández, R.: «El purgatorio docente: entre el desguace de los institutos y la rein-

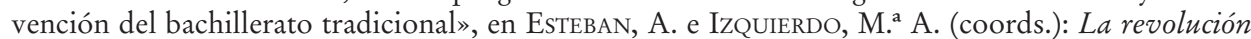
educativa en la Segunda República y la represión franquista, Valladolid, Universidad de Valladolid, 20I4, pp. 8I-I07. Y también "Cirugía de cuerpos y de almas. Totalcatolicismo y educación franquista», en I Congreso Internacional: Territorios de la Memoria. El franquismo a debate, Universidad de Valladolid (20-23 noviembre 2017) (en prensa). 
desmesuradas dimensiones. En efecto, según mi reelaboración, el 36,4\% fueron castigados y el $18,47 \%$ fueron separados de su corporación funcionarial, cifras muy cuantiosas si se comparaban con el resto de las categorías de profesores estatales de Bachillerato e incluso si se cotejan con cualquier cuerpo funcionarial de la educación e incluso si se ponen al lado de la punición sufrida por otros funcionarios 4 . El libro que ahora gloso, dedicado a los catedráticos de Geografía e Historia, viene a acentuar la tesis del alto nivel de punición, que Moreno Burriel evalúa en el $4 \mathrm{I}, 3 \%$. Pero no adelantaré demasiado los acontecimientos y me ceñiré en lo que sigue a una síntesis valorativa del contenido del libro.

La obra se articula en dos grandes partes y cinco capítulos: una primera que presenta la historia del cuerpo de catedráticos de Historia desde su fundación decimonónica hasta la Guerra Civil, y una segunda, mucho más extensa y congruente con el título, que aborda el proceso de depuración de una comunidad profesional entre 1936 y 1943. Consta, además, de un prólogo a cargo del director de la tesis doctoral, Ignacio Peiró; una introducción del autor, y termina con unas breves conclusiones. Rematan magníficamente toda la obra un útil índice onomástico y un apartado de fuentes y bibliografía, dentro del que brilla con luz propia la documentación en forma de nueve anexos (con valiosísimos listados de profesores, centros y tipos de sanciones), y una selección de treinta documentos empleados en el curso de la investigación.

El trabajo de Moreno Burriel no se puede explicar al margen del nicho institucional formado por el Seminario Permanente de Historia de la Historiografía «Juan José Carreras» de la Institución Fernando el Católico de Zaragoza, cuyos extensos méritos no caben en mi recensión, aunque sí se debe subrayar que una de las vigas maestras de sus indagaciones es la idea de que el franquismo supuso una ruptura total y radical con la tradición liberal ${ }^{6}$. De ahí que se niegue rotundamente

4 Véase Cuesta Bustillo, J. (dir.): La depuración de funcionarios bajo la dictadura franquista (1936-1975), Madrid, Fundación Largo Caballero, 2009. Tomando como base lo que ahí se dice y mi interpretación de Negrín FAJARDO, O.: 2005, op. cit.; y GRANA et al.: 20II, op, cit., confeccioné dos cuadros comparativos con otros cuerpos de funcionarios de otras administraciones y de otras categorías de docentes. Véase Cuesta Fernández, R.: 20I4, op. cit., pp. 86 y 92.

s No obstante, me llama la atención que en un texto perteneciente a uno de los capítulos de un libro colectivo publicado en 2017 , un año anterior al de la obra de 2018 que recensiono, su autor afirme, tomando como base su tesis doctoral, que la tasa de castigo llegó al 39,4\%, cifra casi dos puntos inferior a la que menciona en el libro que es objeto de este comentario. Véase Moreno BurRIEL, E.: «La depuración franquista de los catedráticos de Historia de Instituto, 1936-1943», en ForCADELL, C. y FríAs, C.: Veinte años de congresos de historia contemporánea (1997-2016), x Congreso de Historia Local en Aragón, Zaragoza, Instituto Fernando el Católico, 20I7, pp. 372 y 373 [363-375]. En esta ocasión, la separación definitiva afectaría a is catedráticos, al 19,7\%, de los 76 que formaban el escalafón (en parte, la tasa punitiva es más baja porque contempla un total de 76 catedráticos, o sea, cuenta a José Ibáñez Martín, que no sufrió depuración y que en las estimaciones del libro de 2018 no se incluye de modo que en él se maneja un conjunto total de 75 catedráticos depurados).

6 Esta tesis rupturista sin demasiadas contemplaciones ni matices ha presidido la obra del director de esta tesis. Véase, por ejemplo, Peiró Martín, I.: Historiadores en España. Historia de la historia y memoria de la profesión, Zaragoza, Publicaciones de la Universidad de Zaragoza, 2013. Reseñé este libro y critiqué el reduccionismo «rupturista» de su contenido en la revista Historia y Memoria de la Educación, número I (2014), pp. 285-496. 
un supuesto «criptoliberalismo» alojado en el interior del mundo académico vinculado a las artes de Clío.

Como advierte en el prólogo Peiró Martín, el libro es una porción de la tesis doctoral titulada Disciplina y profesión: La Historia en la Segunda Enseñanza, I840-1940, dirigida por el profesor Peiró y defendida en noviembre de 2015 en la Universidad de Zaragoza. El prologuista señala las coordenadas que distinguen el trabajo de su discípulo: «La tesis establecía una diferencia de perspectiva teórica y metodológica respecto a otras investigaciones precursoras [...], más centradas en la pedagogía, los códigos disciplinares y la sociogénesis de un campo profesional» (p. I5) ${ }^{7}$. O sea, esta es una tesis, por decirlo de alguna manera, de historia de verdad y no una «tesis de didáctica» ${ }^{8}$. Quizás cabría decir que la erudición y lo datos empíricos son el fundamento de toda obra historiográfica que se precie, aunque sin categorías analíticas cualquier obra sobre el pasado queda mutilada y aquejada de vacuo empirismo. Quizás ello pueda explicar cómo el prologuista insólitamente dedica buena parte de su perorata preliminar a describir la vida y milagros de uno de los magnates de la corporación objeto de una grave sanción, el catedrático de Historia de Instituto Pedro Aguado Bleye?.

Teniendo tan buen maestro, ya supondrá el lector que no podremos encontrar en este libro mucho más (lo que no es poco) que un excelente trabajo de recopilación de documentación que sirve para hilvanar un discurso historiográfico de gran interés informativo pero carente de conceptualizaciones interpretativas potentes. La tesis de Moreno Burriel incide en la ruptura de la tradición liberal, no en vano, comparado con estudios previos, su conclusión eleva el nivel de destrucción de los catedráticos de Geografía e Historia de Instituto en virtud de la depuración sufrida entre 1936 y I943, pero sobre todo insiste, con razón, en que la originalidad de su trabajo estriba en ceñirse a la exploración muy pormenorizada de los catedráticos de una asignatura (Geografía e Historia) y su mérito consiste principalmente en comprobar sistemática y documentalmente que su índice de castigo $(4 \mathrm{I}, 3 \%)$ es claramente superior al obtenido en anteriores pesquisas y mucho más alto que el resto del profesorado de secundaria (incluso añadiría, por mi parte, que así es en comparación con el resto de los gremios profesionales). Encono punitivo que él, desde su evidente e indisimulada simpatía hacia la obra escolar de la II República, atribuye al peligro ideológico inherente a una disciplina dedicada a la interpretación del pasado, que el régimen de Franco no

$\mathrm{Al}$ conocedor del tema de pronto le viene a la cabeza mi tesis doctoral presentada en la Universidad de Salamanca en 1997, dirigida por José María Hernández Díaz. Véase, una parte sustancial de la misma, en Cuesta FERnÁndez, R.: Sociogénesis de una disciplina escolar: la bistoria, Barcelona, Pomares, 1997.

8 Detrás de esta opinión bien podría atisbarse el secular cisma hispánico entre historiadores generalistas e historiadores de la educación. Los primeros suelen acusar a los segundos de no pasar de pseudohistoriadores por su procedencia del mundo de la Pedagogía. Sin negar la verdad de ese origen pedagógico en su mayor parte, tales juicios no dejan de evocar el machadiano «desprecia cuanto ignora».

9 Cuya figura ya fue tratada en Peiró Martín, I. y Pasamar Alzuria, G.: Diccionario de historiadores españoles contemporáneos, Madrid, Akal, 2002. 
podía dejar de controlar. Desde luego, el gran valor de este trabajo, más que a interpretaciones de este estilo, reside en el uso minucioso de dos colecciones de fuentes muy ricas y principales. En efecto, por un lado, se vale de los expedientes individuales de depuración de 75 catedráticos de Historia que aparecen en el escalafón de 1935 (reelaborado a 3I de diciembre) depositados en el Archivo General de la Administración (AGA), y, por otro, maneja los escalafones corporativos de los catedráticos de Instituto y la normativa oficial reguladora de la situación del profesorado en el periodo estudiado. A todo ello se añaden la consulta y el aprovechamiento de algunas de las investigaciones que han abordado antes el tema de la depuración ${ }^{10}$. En realidad, la máxima aportación de su pesquisa reside en el microanálisis individualizado del cuerpo de catedráticos de Geografía e Historia y la tremenda conmoción sufrida en sus entretelas a causa del salvaje proceso de represión y depuración. Se puede afirmar que, a partir de aquí, disponemos de una imagen más certera de lo que conllevó el purgatorio docente de esta época, pero, además, gracias a la explotación de cada expediente podemos observar el potencial heurístico de tales fuentes a fin de rehacer y traer al presente la vida social, cultural y política de una parte del campo profesional de los catedráticos de Instituto. Así, el autor, siguiendo esa huella documental, dibuja algunos trazos harto pertinentes sobre el perfil socioprofesional de los catedráticos de Geografía e Historia, aunque quizás de manera en exceso descriptiva y con categorías analíticas de escaso fuste sociológico ${ }^{\text {II }}$. No obstante, de sus datos se infiere, como ya se sabía de manera más indirecta y menos rigurosa, el carácter preferentemente conservador del profesorado de Historia de época republicana, ofreciendo una hipotética ubicación ideológica de cada cual, que no carece de precedentes y que posee sumo interés histórico. Empero, el artífice de este progreso en el conocimiento de esta faceta no parece reparar que esta escasa proclividad izquierdista de la corporación contrasta con la tremenda dimensión de la carga punitiva $(4 \mathrm{I}, 3 \%$ castigados con varias y distintas penas y con separación de servicio en torno al $20 \%$ de todo el cuerpo, muy superior al resto del funcionariado $)^{12}$.

Aquí se echa en falta la consulta de estudios sobre la depuración funcionarial en otras categorías dentro y fuera de enseñanza y de otros servidores públicos no vinculados a la educación (tales como Correos, jueces, ingenieros, etc.). Eso le permitiría esbozar una evaluación comparativa a todas luces necesaria. A algo de esto responde un texto mío que Moreno Burriel no maneja, a saber, Cuesta Fernández, R.: 20I4, op. cit.

" Al respecto, cabe mencionar que la vida y milagros de cada catedrático se introduce en la narración del texto corrido, de forma que esta retahíla de 75 vidas profesionales ocupa la friolera de 176 páginas, lo que hace tediosa la lectura de esa parte del texto y pide a gritos llevar tal información a una especie de diccionario a modo de anexo. Con todo, los datos que él aporta y los que ofrece Mainer Baqué, J.: Inventores de sueños. Diccionario bioprofesional de pedagogos y didactas de Geografía, Historia y Ciencias Sociales hacia 1936, Zaragoza, Institución Fernando el Católico, 2009, hacen factible levantar un mapa biográfico muy ilustrativo del campo profesoral vinculado a la enseñanza de las ciencias sociales, que además se complementa perfectamente con el diccionario de Peiró Martín, I. y Pasamar Alzuria, G.: op. cit.

${ }_{12}$ Aquí hay una diferencia de datos si atendemos al libro comentado (41,3\% de sancionados y I8,6\% de expulsados del cuerpo) o su capítulo de 2017 que estima que son un $39,4 \%$ los primeros y un $19,7 \%$ los segundos. Véase Moreno Burriel, E.: 20I7, op. cit., pp. 372 y 373. 
Sin duda, tomando como base la intensa poda de la profesión es posible mantener y alimentar con sólidas pruebas la tesis de que hubo una ruptura profunda de la tradición liberal. La cosa, sin embargo, como se verá, es más compleja. En efecto, sea la tasa de sancionados el 4I,3\%, sea el 39,4\% (las dos cifras que Moreno Burriel maneja en 2018 y 20I7), supone una altísima intensidad en el castigo y un cambio notable en el cuadro de los individuos del escalafón de 1935 vigente a la altura del i8 de julio del 36, que, según el propio autor, había quedado reducido al 50\%, lo que obligó a aderezar unas oposiciones «de excepción» en 1940, en doble turno (restringidas y libres) con reconocimiento de «méritos de guerra», merced a las cuales entraron 20 nuevos catedráticos. Conviene decir que, a pesar de los pesares, los que accedieron, en su mayor parte, is sobre 20, habían sido reclutados bien en los cursillos republicanos de 1933 aprobados por I4 de los nuevos catedráticos y los de 1936 seguidos por i de ellos. En una palabra, un amplio segmento de la nueva plantilla se dotó de profesorado reclutado por la República a fin de sustituir a la enseñanza religiosa y atender a la consiguiente demanda de nuevos centros. Por lo tanto, hubo cambio extraordinario y significativo, pero endogámico y hasta cierto punto dentro de las reglas del campo profesional. Sin minimizar un ápice el efecto de este abominable y forzado recambio profesional, sí queremos destacar que la depuración actuó como un execrable purgativo que expulsó a la parte más señalada (en torno al $20 \%$ ) y atemorizó al resto, bien con castigos de menor entidad, bien con la inseguridad individual y la amenaza permanente de ser «revisado».

Ahora bien, volviendo a los cálculos de Moreno Burriel, es muy vidente que las fuentes que maneja para los catedráticos de Historia mejoran lo sabido hasta ahora y sus cifras de castigo (entre el 39 y el 41\%, con un índice de expulsión en torno al $20 \%$ ) se pueden dar por aproximaciones originales y muy documentadas, pero hay un extremo que debilita su análisis al incurrir en una comparación confusa e inadecuada ${ }^{13}$. Veamos:

Los catedráticos sufrieron en mayor medida la depuración que la media de los numerarios de otras disciplinas, en conjunto alcanzaron casi catorce puntos de diferencia. Los datos conocidos hasta el momento sitúan la depuración de los catedráticos de instituto en torno al $27 \%$, mientras que nuestro estudio la aumenta hasta el $41 \%{ }^{14}$.

En efecto, el trabajo más sistemático hasta ahora sobre la depuración del conjunto del profesorado de los institutos se basa en los 2.445 expedientes del AGA que manejó el equipo de la Universidad de Málaga, cuyos resultados arrojan la

${ }_{13}$ Yo mismo intenté, a partir de cruzar escalafones con datos provenientes del equipo de Málaga, un cálculo de la depuración de los catedráticos de Historia y obtenía un índice de $33,8 \%$ castigados y de $20 \%$ de separación del cuerpo. Véase Cuesta Fernández, R.: 20I4, op. cit., pp. 94-97. Ahora , en este caso, el trabajo de Moreno Burriel mejora el mío, porque él sí toma en cuenta el hecho de que el escalafón de 1935 tuvo una actualización a fecha de 3I de diciembre de ese año (con ocho personas más ingresadas en las oposiciones del 35), aspecto que yo no consideré. Además mi cálculo partía de fuentes menos directas, por lo que bienvenida sea la corrección al alza que se desprende de la obra que se comenta.

${ }^{14}$ Moreno Burriel, E.: 20I8, op. cit., p. 340. 
cifra de $27,4 \%$ como tasa de castigo $\left(28,4 \%\right.$ hombres y $20,5 \%$ mujeres ${ }^{15}$. Sorprendentemente Moreno Burriel no advierte que este trabajo escruta el universo de la totalidad de los profesores y profesoras, pertenecientes a seis distintas categorías, y no solo se refiere a los catedráticos. Nosotros, en su día, desagregamos la categoría docente de catedráticos de todas las asignaturas y el resultado de sanción en el cuerpo lo establecimos en el $36,4 \%$, cifra ya mucho más cercana a la que obtiene el propio Moreno Burriel, que parece ignorar que los catedráticos en los institutos de 1935 apenas eran poco más del $30 \%$ del total de docentes ${ }^{16}$. De modo que la comparación debe hacerse con el conjunto del cuerpo de catedráticos y no con todo el universo profesoral. Así, en mi trabajo había quedado resaltado cómo los catedráticos en su conjunto habían sido sancionados con más virulencia que otras subcategorías docentes de inferior status, y ello me llevaba a preguntarme por las razones de ese diferencial. Esa particularidad no es, pues, consecuencia o fruto de ejercer como docente de Historia, sino que más bien se muestra como una marca propia del cuerpo, porque sea el $36,4 \%$ de todos los catedráticos que mantengo en mis trabajos o el $4 \mathrm{1}, 3 \%$ de los de historia que estima el estudio de Moreno Burriel, el caso es que cualquiera de las dos cifras es superior a la de otros cuerpos funcionariales. Ello obligaría a interrogarse cómo fue posible tal escarnio en una corporación funcionarial de talante más bien morigerado.

Hoy por hoy, sabemos que una tasa de sanción en torno al $40 \%$, como la que defiende Moreno Burriel para los catedráticos de Historia de los institutos, es manifiestamente más alta, porcentualmente hablando, que la de los maestros o la de los otros profesores de segunda enseñanza no catedráticos, y, por añadidura, también queda por encima incluso de las categorías más hostigadas y penadas del orbe funcionarial como fueron Correos y Telégrafos (34,7\%), catedráticos de Universidad $(32,1 \%)$ o inspectores de Primaria $(37,5 \%)^{17}$. No es este el lugar de desarrollar un tema que merecería más atención cual es el «techo» de sanción factible para la reproducción de una dictadura de tintes fascistas. Aquí habría que recurrir de nuevo a la comparación con regímenes semejantes y no estaría de más entender la entrega de una parte del Bachillerato a centros de la Iglesia católica como una forma indirecta de destrucción corporativa. En todo caso, queda pendiente la labor historiográfica de ofrecer, a partir de procedimientos homologables de fuentes y recuento, una visión de conjunto de la brutal cirugía sufrida por los cuerpos docentes y por el conjunto del espacio funcionarial, piezas imprescindibles en el funcionamiento del Estado y las consiguientes formas de dominación a través de la fuerza y de la «violencia simbólica».

Llegados aquí es preciso rendir un juicio muy positivo sobre la aportación empírica y documental de esta investigación, que refuerza y precisa con un gran despliegue de información la idea ya conocida de la extremada saña que comportó

Sanchidrián Blanco, C.; Grana Gil, I. y Martín Zúníga, F.: 2oit, op. cit.

16 El 31,31\%, según SANChIDRIÁn et al:: 20II, op. cit. Véase Cuesta FernándeZ, R.: 2104, op. cit.

${ }_{17}$ Salvando la heterogeneidad de fuentes y situaciones que hacen difícil avalar la completa precisión de la comparación. Los porcentajes mencionados provienen de CUESTA FERNÁNDEZ, R.: 2OI7, op. cit. (en prensa). 
la depuración de los catedráticos de Instituto. Por lo demás, el apunte de vidas profesionales de los depurados que adereza el autor del libro constituye una invitación a efectuar una reconstrucción más rica del campo profesional, utilizando quizás un marco teórico y explicativo que superara el horizonte interpretativo del Seminario Juan José Carreras de Zaragoza, que mantiene, sin demasiados matices, la doctrina de la ruptura abrupta de la tradición liberal. Sin duda, las cifras aportadas por Moreno Burriel apuntan hacia un castigo muy duro y ejemplar, pero no debemos olvidar que los cuerpos docentes permanecieron funcionando durante el franquismo con una lógica que, a pesar de la parcial eliminación y el total amedrentamiento de sus miembros, se remonta al siglo XIX y que el reemplazo de sus componentes en 1940 y posteriormente, siendo muy penoso y grave, no fascistizó del todo el ethos heredado de una larga tradición elitista y de corte liberal ${ }^{18}$. En realidad, hubo cambios bruscos pero también continuidades, porque, al fin y a la postre, los cuerpos docentes, como parte de la burocracia, acaban aceptando esa «ilusión del Estado» de la que gustaba hablar Marx e involuntariamente insertaron su existencia y su práctica (babitus docente) en las ondas más largas de la transición de un modo de educación tradicional-elitista a otro tecnocrático de masas. El cuerpo de catedráticos de Historia de Instituto sufrió un desolador despojo individual y colectivo como muestra el trabajo de Moreno Burriel, pero el sistema de razón corporativa prosiguió al servicio de los nuevos dueños del Estado. Ya en los años sesenta, la explosión cuantitativa y la rápida feminización de sus componentes abriría paso a una nueva corporación llamada a perecer en forma pacífica reduciendo su esencia corporativa a la de mera «condición», como se recoge en 1990 en la Ley General de Ordenación del Sistema Educativo (LOGSE) ${ }^{19}$. Lo que ni siquiera ocurrió con la cruel cirugía de cuerpos y almas del franquismo, aconteció suavemente y como si nada, con la consolidación del modo de educación tecnocrático de masas.

18 Desde luego, el autor orilla las categorías que se manejan en investigaciones como la de Mainer Baqué, J.: La forja de un campo profesional. Pedagogía y didáctica de las Ciencias Sociales en España (I900-I970), Madrid, CSIC, 2009, o la que se contiene en CUESTA FERNÁNDEZ, R. y MAINER BAQUÉ, J.: «Guardianes de la tradición y esclavos de la rutina: historia del campo profesional de los catedráticos de Instituto", Historia y Memoria de la Educación, número I (2015), pp. 35I-393. El sutil entramado de cambios y continuidades en los aledaños del Estado franquista también se puede apreciar en Mainer Baqué, J. y Mateos Montero, J.: Saber, poder y servicio. Un pedagogo orgánico del Estado: Adolfo Maíllo, Valencia, Tirant lo Blanch, 20 II.

19 Valga como muestra la comparación numérica de los registros de los escalafones de catedráticos de 1941 y 1963. En el primero la cifra total de catedráticos de Historia llega a 69 (en 1935 eran 76) con un $7,2 \%$ de mujeres, en cambio, en el segundo se alcanzan los II4 con un índice de feminización 19,2\%. En el de 194I pervive la escala reducida del cuerpo mientras que en el de 1963 se empieza a notar esa «revolución silenciosa» que, dentro de pautas tecnocráticas, empezó a cambiar la educación a pesar del régimen franquista. Véase Escalafón de los Catedráticos Numerarios de Institutos Nacionales de Enseñanza Media, situación a I de octubre, Revista de Información Universitaria, 194I, y Escalafón de los Catedráticos Numerarios de Institutos Nacionales de Enseñanza Media, situación a I de enero de 1963, Revista de Enseñanza Media, número 135-136 (1964). 
